\title{
One way out of a patent quagmire
}

The European Patent Office is caught in a taxonomic trap unintentionally set by its constitution. The only sensible way out that favours supporters of biotechnology comes with its own set of problems.

LAWYERS are fond of fuzziness, for obvious reasons. So they must adore the European Patent Convention, which has its fair share of legal ambiguities, is outdated, and is obstructing the development of industrial plant and animal biotechnology in Europe in a debate that rests on one of science's great but fuzzy disciplines: taxonomy. Ultimately the convention will have to be rewritten, but in a way that is bound either to undermine the biotechnology industry or enrage those who oppose it on ethical grounds.

The convention forms the constitution of the European Patent Office (EPO) - a body that currently finds itself at an impasse that prevents it from patenting genetically modified plants or animals, to the great frustration of its senior officials and of a burgeoning industry that they seek to serve. The convention was written in 1973, just before the advent of recombinant DNA technology, though it is only now that its shortcomings are coming home to roost.

Every one of the eight patents on higher organisms issued by the EPO since 1989 has been attacked on ethical grounds. Opponents have usually invoked the article in the convention which states that patents should not be issued if they are contrary to 'l'ordre publique'. This 'morality clause' was inserted to exclude, for example, pornography and sophisticated weaponry from patentability, and anti-biotechnologists have never deployed it successfully.

The tide turned in February last year, during an appeal against a patent granted to the Belgian company Plant Genetics Systems (PGS) covering a procedure for producing herbicide-resistant plants, as well as the plants and seeds arising from the process. The 'opposition board', which is the first port of call for such appeals, insisted that the scope of the patent be restricted to exclude the plants produced, not on morality grounds, but rather on the basis of another exclusion clause in the convention, intended originally to protect plant breeders' rights. The clause states that modified animals and plants are patentable, but that new animal and plant varieties are not. That is where taxonomy's fuzziness has added to the lawyers' fun. Its first contribution was to give opponents the wherewithal to persuade the opposition board that plants can be considered collections of plant varieties and are therefore not patentable. Hence the impasse.

With hundreds of plant and animal applications pending, the EPO has sought ways of overturning that ruling on the basis of conflicting precedents, but, following the collapse of an opportunity last week (see page 178), so far in vain. It could, without significant further ado, change its implementation rules, instructing patent examiners and its legal staff to note that, for the purposes of patenting, a modified species is not to be considered as a collection of varieties for the purposes on patenting. Because such a unilateral judgement would cause an outcry, the EPO might sensibly wish to await the passing by the European Parliament and ministers of the European Commission's new directive on biotechnology which, in its current form, explicitly backs such a move. The EPO is not a European Union body, but an EU directive would give the office the political weight it requires to dare to change its implementing rules, if the directive is passed as it stands.

That is a big "if". The approach flies in the face of some countries' reluctance to support genetic technologies, and is also contrary to scientific sense. The definitions of variety and of species have indistinct boundaries. Introducing genetic modifications adds yet another source of ambiguity to the debate - and one that can span taxonomic categories. Attempts to forcibly restrict the legal definition of 'variety' would surely fail - no form of words seems able to bypass that fundamental fuzziness.

Unfortunately for the EPO, the only sustainable way out of this impasse will encounter lengthy delay, controversy, and hostile voters: it must persuade its member states to rewrite the convention to remove the obstacle to patenting varieties. Such a step has a precedent: a few years ago the convention was changed to extend the proprietary period of pharmaceuticals. The current issue is much more controversial - years of work on the convention could end in political failure. But, if the law is to make sense, the EPO has no other choice.

In the meantime, the EPO can only hope that some expedient form of words can after all be found that will temporarily fill the gap, while its ethically motivated opponents should give thanks for taxonomy's limitations.

\section{Defend studies of science}

Stanford should be developing programmes that bring together science and the humanities, not closing them down

SCIENCE, Technology and Society (STS) is a discipline taught and studied in many different forms in the United States, but always tries to engage experts in politics and economics, as well as sociology, in an exchange of ideas with scientists and engineers. Regrettably, the fact that it was spawned in the 1960s and early 1970s, and that some of its practitioners have embraced extreme positions (characterizing science as a social construct, for example), has fuelled a backlash against it. Some scientists have decided that, in these straitened times, criticism from social scientists is a luxury that they can do without.

Senior faculty at Stanford University in California don't think that: as their university is arguably the intellectual home of the silicon technology which is now transforming our society at an unprecedented rate, it would be a shame if they did. But the university is considering the abandonment of courses in STS (see page 183) because its interdisciplinary status makes it unrewarding for faculty members to spend time on it, rather than on more pressing demands inside their own departments. That is a problem for all interdisciplinary projects: however good they are, they can be the first to suffer from financial retrenchment.

Last year, some staff at Stanford put forward an ambitious proposal to expand STS into graduate teaching and research, thus providing the intellectual impetus to get faculty involved, raise standards and secure the programme's future. The engineering school says it can't afford it. The university must now step in, save the programme and establish a structure that will rescue it from the game of pass-the-parcel that has afflicted it since its 1971 inception.

The chasm between science and the humanities is still huge. If Stanford - excellent in both - won't keep trying to bridge it, who will? 